\title{
Integrated undergraduate optical engineering education at West Point
}

Daniel Litynski, Andre Sayles, Barry Shoop, Bradford Tousley

Daniel M. Litynski, Andre H. Sayles, Barry L. Shoop, Bradford C. Tousley, "Integrated undergraduate optical engineering education at West Point," Proc. SPIE 2525, 1995 International Conference on Education in Optics, (13 October 1995); doi: 10.1117/12.224006

Event: SPIE's 1995 International Symposium on Optical Science, Engineering, and Instrumentation, 1995, San Diego, CA, United States 
Integrated undergraduate optical engineering education at West Point

Daniel M. Litynski, Andre H. Sayles, Barry L. Shoop, and Bradford C. Tousley

Department of Electrical Engineering and Computer Science and Photonics Research Center

U.S. Military Academy, West Point, New York 10996-1787

\begin{abstract}
$\underline{\text { ABSTRACT }}$
In meeting the growing demand for graduates who have a background in optical engineering, the Department of Electrical Engineering and Computer Science and the Photonics Research Center at the U.S. Military Academy have jointly developed an instructional program that familiarizes every student with principles of laser operation and provides undergraduate research opportunities in optics for electrical engineering majors and others. The program includes a series of laboratory demonstrations in the Photonics Research Center for students in all majors during their sophomore year. For electrical engineering majors, the program also offers a senior level photonics engineering course, advanced individual study in laser applications, and a variety of capstone design projects. Advanced individual study may include up to three semesters of experimental research similar to masters degree thesis work in a graduate program, while the capstone project is accomplished in one semester by design teams based on the design-build-test methodology. Both types of projects address real-world requirements specified by faculty advisors or external mentors. Our integrated approach to optics education supports ongoing state-of-the-art research in the Photonics Research Center and provides technically qualified graduates to meet the demands of the field Army of the 21st century.
\end{abstract}

Keywords: optics education, undergraduate research, undergraduate photonics engineering, capstone design, West Point

\title{
1. INTRODUCTION
}

Photonic technologies underpin many communications, signal processing, and computational systems. The growing number of commercial and military applications for optics has been a driving force behind the evolution of the undergraduate optics program at the United States Military Academy (USMA). Military research and development programs have benefited from emphasis on technology transfer from commercial applications to military systems. Similarly, dual-use developments originating in the military sector have been of benefit to private industry. This commonuse approach to military and commercial research and development has prompted USMA to implement an integrated education program in optics that is compatible with the focus of industry as well as the Army. This program includes laser familiarization for all 4000 students at West Point and more concentrated studies for a fairly large sample of physics, chemistry, and electrical engineering majors. The optical engineering education program is primarily based on conventional courses in applied optics, laser physics, and photonics engineering. However, the military sector must also focus on extending the same principles to weapon systems applications and soldier protection from radiation, and address such applications in the optics education process. This paper discusses the evolution of these courses and subsequent integration with the capstone design program, the undergraduate research program, and the experimental work in the Photonics Research Center (PRC).

\section{OPTICAL ENGINEERING AND THE CURRICULUM}

The U.S. Military Academy ensures graduates enter the Army with a balanced undergraduate education that develops basic knowledge in the sciences, engineering, and humanities. Students typically spend three semesters on required science and humanities courses before starting a majors program in a particular discipline. Cadets in an ABETaccredited engineering program take approximately 43 courses during a four year or eight semester enrollment. Thirty-one of those courses make up the required humanities, basic science, and engineering core curriculum, followed by twelve field courses which lead to the engineering major. The Academy keeps pace with the technological needs of the Army by requiring all graduates to take a series of at least five engineering courses within the core regardless of whether the student is majoring in mathematics, science, engineering, or the humanities. Typically, the five courses fall within a single 
engineering discipline, lead to an understanding of the engineering process, and culminate with a capstone design project. A total of seven five-course "core engineering sequences" are available for the cadet to choose from. ${ }^{1}$

\title{
2.1 The electrical engineering curriculum
}

The mission of the Department of Electrical Engineering and Computer Science is to educate future national defense leaders in the theory and practice of electrical engineering and computer science -- supporting USMA's overall purpose of "providing the nation with leaders of character who serve the common defense." The 44 course curriculum shown in Table 1 includes the 26 common core courses necessary to produce well-rounded officers for military service, the five course electrical engineering core sequence, 12 additional courses necessary for competence in electrical engineering, and a one credit seminar which is primarily oriented towards exposing students to professional practice. The 12 field courses, seminar course, and the five course core engineering sequence provide a solid foundation in the discipline. The photonics engineering course, EE483, is usually taken during the final semester. The core courses, the breadth of electrical engineering, and a strict four year completion requirement dictate a program that is very carefully designed to meet both academy and accreditation requirements.

Freshman Year
\begin{tabular}{|c|c|}
\hline $\begin{array}{c}\text { Discrete } \\
\text { Math }\end{array}$ & $\begin{array}{c}\text { Differential } \\
\text { Calculus }\end{array}$ \\
\hline Chemistry & Chemistry \\
\hline History & History \\
\hline Psychology & $\begin{array}{c}\text { Computer } \\
\text { Science }\end{array}$ \\
\hline English & \begin{tabular}{c} 
English \\
\hline
\end{tabular} \\
\hline
\end{tabular}

Sophomore Year
\begin{tabular}{|c|c|}
\hline $\begin{array}{c}\text { Integral } \\
\text { Calculus }\end{array}$ & $\begin{array}{c}\text { Foreign } \\
\text { Language }\end{array}$ \\
\hline Physics & Physics \\
\hline $\begin{array}{c}\text { Foreign } \\
\text { Language }\end{array}$ & EE365A \\
\hline Economics & $\begin{array}{c}\text { Political } \\
\text { Science }\end{array}$ \\
\hline Philosophy & $\begin{array}{c}\text { Terrain } \\
\text { Analysis }\end{array}$ \\
\hline & MA364 \\
\hline
\end{tabular}

Junior Year
\begin{tabular}{|c|c|}
\hline $\begin{array}{c}\text { English } \\
\text { Literature }\end{array}$ & $\begin{array}{c}\text { Internat'1 } \\
\text { Relations }\end{array}$ \\
\hline $\begin{array}{c}\text { Probability } \\
\text { \& Statistics }\end{array}$ & Leadership \\
\hline EE302 & EE363A \\
\hline PH365 & EE381 \\
\hline EE475 & EE377 \\
\hline EM302 & EM301 \\
\hline
\end{tabular}

Senior Year
\begin{tabular}{|c|c|}
\hline $\begin{array}{c}\text { Military } \\
\text { History }\end{array}$ & $\begin{array}{c}\text { Military } \\
\text { History }\end{array}$ \\
\hline EE383 & Law \\
\hline EE407 & EE408A \\
\hline EE477 & EE487A \\
\hline EE471 & EE483 \\
\hline & $\begin{array}{c}\text { EE400A } \\
\text { Seminar }\end{array}$ \\
\hline
\end{tabular}

\author{
Required Courses: \\ EE302 Intro to Electrical Engineering I \\ EE363A Intro to Electronics \\ EE365A Digital Computer Logic \\ EE377 Electric Power Engineering I \\ EE381 Signals and Systems \\ EE383 Electromagnetic Fields \\ EE407 Electronics Design I \\ EE408 Electronics Design II \\ EE471 Automatic Control Systems \\ EE475 Intro to Computer Architecture \\ EE477 Communications Systems
}

$\begin{array}{ll}\text { EE483 } & \text { Photonics Engineering } \\ \text { EE487A } & \text { Telecommunications } \\ \text { EM301 } & \text { Thermodynamics } \\ \text { EM302 } & \text { Statics and Dynamics } \\ \text { PH365 } & \text { Modern Physics } \\ \text { MA364 } & \text { Engineering Math } \\ & \\ \text { Elective Courses: } \\ \text { EE486 } & \text { Solid State Electronics } \\ \text { EE488B } & \text { Microwave Engineering } \\ \text { EE489 } & \text { Advanced Individual Study }\end{array}$

Table 1. Typical electrical engineering program. ${ }^{2}$

\section{$\underline{2.2 \text { Advanced individual study }}$}

Undergraduate research opportunities are generally available to students who have received constructive credit (or validation) for one or more of the 26 core courses. Since every student at USMA must enroll in a minimum of five courses 
each semester, those who have received constructive credit for more than one course may fill out their schedule with individual research projects through the advanced individual study course, EE489. This process often leads to projects that extend over several semesters, with a course grade being awarded at the end of each semester. In the electrical engineering program, the better students are also permitted to work on an individual research project in lieu of one of the senior-level elective courses. Cadets desiring to substitute advanced individual study for a standard course must work with a faculty advisor to ensure that the project will provide the proper mix of engineering science and engineering design. Those who enroll in the advanced individual study course work under the direct tutelage of a faculty member who provides extensive guidance, resources, and support. Because the students are at the undergraduate level, the faculty advisor often spends several hours per week discussing theoretical concepts and experimental procedures. The typical results are excellent and often comparable to masters level work. A major difference between undergraduate research and graduate research is the investment of time required of the faculty advisor.

\section{$\underline{2.3 \text { Capstone design program }}$}

The electrical engineering senior design project covers the entire sixteen week final semester of the program. Prior to that final semester, students are organized into design teams and required to prepare a proposal that delineates project requirements in technical terms and outlines an initial strategy for solving the design problem. Design teams include majors from a variety of disciplines, making it impractical to administer all students by using a single capstone design course. Within the program for electrical engineering majors, the computer engineering and electrical systems stems each conclude with a 3.5 credit hour project course that covers digital and analog system design, respectively. Cadets taking only the five course electrical engineering core sequence do not have the same background as the majors, but serve on the same design teams. Their contribution is expected to be approximately $75 \%$ of the typical effort from an electrical engineering major. The sequence students are assigned to a separate 3.0 credit hour project course that describes their likely contribution to a group design project. Additional design team members may include majors from other disciplines, such as engineering management or computer science, who receive credit for design project contributions through a standard course in their discipline or an undergraduate research course.

Design problems are coordinated with department faculty and, where appropriate, outside organizations such as the Army Research Laboratory. Students are required to provide three prioritized choices from the list of available projects. They are also permitted to name up to two additional students whom they may want to work with on each project. Based on the sign-up process, faculty members determine which projects will be completed for the current academic year. Typically, more projects are offered than can be covered by the number of students available. Electrical engineering majors are first assigned to project teams based on a combination of student preferences for projects, student preferences for team members, and instructor recommendations. Before projects are offered, requirements are established for the number of electrical engineering majors from each of the two stems, along with the suggested number of sequence students and majors from other disciplines. The target group size for each design team is four electrical engineering majors plus students from other disciplines as needed. After three to five electrical engineering majors are assigned to each project, the core sequence students are added to teams based on a number of considerations, including past performance, individual skills, choice of project, team leader personality, and advisor opinion or preference. When possible, engineering management majors are added on a one-per-team basis.

Once all majors and sequence students have been assigned to a design team, a team leader is designated based on the best qualified volunteer for that position. Each design team then goes through a series of work sessions to analyze requirements and identify the need for students from other disciplines. The supervising faculty member then works with professors from other disciplines to obtain the services of additional cadets as requested by design team leaders. Team compositions for academic year 1994-95 included 25 electrical engineering majors, six computer science majors, six engineering management majors, and one major from each of physics, life sciences, and foreign languages. All students who were not electrical engineering majors were either in the five course electrical engineering core sequence or the computer science program. 
The capstone design course requires each design team to produce a physical system that is based on interdisciplinary principles drawn from throughout the four-year curriculum. Nearly all projects have analog, digital, and optical components. During the spring of 1995, three of the eight projects had major optical engineering components.

\subsection{Academic individual advanced development}

The four-year experience at West Point includes a baseline program and an enrichment program. The baseline is the standard to be met by graduates in each of the three developmental stems of academic, military, and physical. Some form of enrichment beyond the baseline must be accomplished by all students. The academic baseline standard specifies, among other things, 40 courses as the minimum number necessary for meeting field of study requirements and for graduation. The vast majority opt to go beyond the academic baseline and to major in a discipline. Baseline requirements are also set for physical and military development. Every cadet must also pursue a summer activity that goes beyond the academic, physical, or military baseline requirements. Most students pursuing academic development beyond the classroom select a program related to their discipline of study. The Department of Electrical Engineering and Computer Science offers summer research opportunities at various government and related organizations throughout the country, with the most popular locations being Army Research Laboratory facilities. Students who prefer to remain at the Academy during the summer can select research topics offered by the Photonics Research Center and the department. Summer projects are usually three to five weeks in duration but can be as long as eight and can be continued during the fall semester in lieu of an academic course if all other qualifications are met. A 3.0 credit academic course at West Point is programmed to require approximately 120 hours of student effort by the end of a semester. Similarly, a three-week summer research project at 40 hours minimum per week will require 120 student hours. Electrical engineering students participating in summer programs away from West Point most often serve as project officers or junior engineers.

\section{$\underline{2.5 \text { Creation and evolution of optics courses }}$}

Formal instruction in optics and related topics is available in several courses at the Academy. A brief orientation on how lasers work comes at the end of the first semester of sophomore classical physics. The junior-level modern physics course provides a block of instruction on basic laser principles and associated commercial and military applications. The Department of Physics offers courses in applied optics and laser physics, as well as a solid state physics course that includes a discussion of laser materials. The Department of Electrical Engineering and Computer Science offers one course in photonics engineering. The three primary courses are identified in Table 2 and discussed in detail. The first author created PH485 and EE483 approximately 20 and 15 years ago, respectively, and the other authors have directed EE483 in recent years.

\begin{tabular}{|l|l|l|}
\hline NUMBER & \multicolumn{1}{|c|}{ COURSE TITLE } & \multicolumn{1}{c|}{ ACADEMIC DEPARTMENT } \\
\hline PH384 & Applied Optics & Physics \\
\hline PH485 & Laser Physics & Physics \\
\hline EE483 & Photonics Engineering & Electrical Engineering and Computer Science \\
\hline
\end{tabular}

Table 2. Photonics and optics courses.

The applied optics course provides a basic introduction to classical geometric, wave, and quantum optics. It covers lenses, mirrors, light transmission in optical media, diffraction, interference, and polarization. Applied topics taught in the course include optical wave guides, fiber optics, Fourier optics, holography, imaging, atmospheric effects, detectors, and television. Classroom lectures are supplemented with laboratory demonstrations. The Department of Physics also offers the laser physics course, which provides a combined theoretical and experimental investigation of optical radiation generation, propagation and detection. Principles of electromagnetics, physical optics, geometric optics, and atomic structures are covered in detail and demonstrated through physical systems when possible. Laser experiments are an integral part of the course. 
The photonics engineering course offered by the Department of Electrical Engineering and Computer Science begins with a review of fundamental electromagnetic field theory, addressing essential concepts including the wave equation, Fresnel equations, polarization considerations, and dielectric interface interactions. The course then introduces geometric/Gaussian optics analytical techniques including matrix methods of optical systems analysis. Cadets study resonators and lasers, followed by instruction on semiconductor optoelectronics, to include emitters (LED's and lasers) and detectors. Three lessons are devoted to acousto-optic and electro-optic modulating techniques and systems, while the final seven lessons in the course focus on two-dimensional and fiber optic waveguides, and fiber optic communications systems. The five laboratory periods enhance the lecture material in scope and timing and cover geometrical optics, semiconductor photo-emitters, acousto-optic modulation devices and techniques. The final two laboratories require the students to organize in teams to design, build and test a complete fiber optic heterodyne communications link. The optics laboratory facility has four student stations with light sources, oscilloscopes, acousto-optic modulators and drivers, photodetectors, optical fibers, and assorted optical hardware. The laboratory has a 486 based PC laboratory setup which includes extensive optical design software to determine expected performance. The laboratory is equipped with a complete optical spectrum analyzer and stabilized light source capability (LED and semiconductor laser) at $.85 \mathrm{~mm}, 1.3 \mathrm{~mm}$, and $1.55 \mathrm{~mm}$ with single mode, multimode, and graded index fiber capability. The laboratory has a holographic laser recording system, a high power, single frequency Argon laser, and high speed modulated semiconductor lasers and attenuators. The laboratory has recently been equipped with a Spectra Diode Labs (SDL) high power semiconductor laser, which students are using to characterize nonlinear optoelectronic modulation photodetectors. The laboratory is well equipped for student instruction and undergraduate research, and has dramatically enhanced the understanding of photonics devices and systems.

\section{THE PHOTONICS RESEARCH CENTER}

\subsection{Evolution, mission, and objective}

In 1987, the Army established the Photonics Research Center at the U.S. Military Academy to educate cadets and faculty in laser technologies. ${ }^{3}$ The mission of the PRC is to conduct basic research and teach laser fundamentals. The primary objective is to satisfy the Army's need for officers who have an understanding of laser fundamentals and laser applications. The target audience includes every cadet at the Academy and a significant number of junior faculty who return to Army field duty after three years as an instructor. Faculty members who have active research projects in the Photonics Research Center are jointly appointed to the PRC and either the Department of Chemistry, the Department of Physics, or the Department of Electrical Engineering and Computer Science. The photonics research program includes spectroscopy, properties of wide bandgap semiconductors, multiple quantum well device applications, silicon optoelectronic circuits and devices, and optical signal processing. The electrical engineering and computer science research program is particularly attractive to undergraduate student participation due to emphasis on laser and device applications. Each year, a large number of student projects are planned prior to the beginning of the fall semester. Although some of the opportunities are parts of larger faculty experiments, the PRC also offers small, independent projects that include independent work.

\section{$\underline{3.2 \text { Current research areas }}$}

The Photonics Research Center is a consortium of researchers from physics, chemistry, and electrical engineering \& computer science Since 1987, the facility has grown to ten major experimental programs supported by a multi-million dollar investment of major equipment items. Chemistry and physics experiments tend to be oriented towards spectroscopy and applied science, while the electrical engineering \& computer science faculty focus on engineering applications. Several of the current experiments that involve students are discussed in the following sections.

\subsubsection{Silicon optoelectronic circuits and devices}

For the last four years, the investigation of silicon optoelectronic devices has proven to be an excellent topic for undergraduate research. Five students have worked on different aspects of the silicon device experiment during the past three years. A typical project includes a review of previous work, development of new or improved circuits or devices, 
layout and fabrication of an integrated circuit chip, experimentation, and development of theoretical concepts. This project began several years ago with the fabrication of an assortment of photosensitive devices in a conventional CMOS process through the ARPA/NSF sponsored MOSIS foundry service. These devices quickly generated a virtually unlimited number of opportunities for student research. For individual photodiodes, possible investigations include quantum efficiency dependence upon device size and shape, device type, wavelength of incident light, spot size of incident light, linewidth of the laser source, or proximity of one device to another. By requiring the detector to convert the incident light to a TTL level voltage, the students can investigate a large number of integrated resistive load configurations, buffering requirements, bandwidth, or circuit speed. The conversion of photocurrent to a voltage can be accomplished with many different MOSFET configurations that provide nonlinear resistance effects. These circuits can be optimized for individual parameters such as minimum optical power, fastest operating speed, or least chip real estate. Optimization can also be based on any combination of such parameters. The MAGIC layout editor for integrated circuits is available for layout of new chips. This type of project complements the typical undergraduate electrical engineering program because prerequisites are limited to modern physics, basic electrical circuits, introductory electronics, and solid state physics or electronics. Faculty advisors mentor cadets in their independent study of photodetector theory, laser fundamentals, and simple geometrical optics. Each investigation tends to uncover several new questions that can be pursued by future student researchers who will generate new solutions that can be implemented on an integrated circuit chip and tested for validity.

\subsubsection{Optical data storage in photorefractive crystals}

At least five undergraduate students have individually studied the theory and completed experiments that demonstrate the storage and retrieval of optical data using a commercial lithium niobate crystal. Although a fairly expensive experimental setup is initially required, many different opportunities for research become available once the experiment has been established. In the past year, the undergraduate research has focused on the development of electronic circuits that correctly detect and display the output optical data when it is in the form an array of parallel light beams. Students have increased from a single bit of data to a four by four array or sixteen bits of data. As the array size increases, the electronic detection and display system becomes significantly more complex. An attractive option for this project is the opportunity to design a custom detector array to match the expected output from the photorefractive crystal. Student requirements can range from layout and fabrication of an integrated circuit chip for detection only, to development of a chip that detects the output data and encodes it for input into a display device.

\subsubsection{Advanced gallium arsenide (GaAs) research}

During the 1993-94 academic year, a student designed and built an optical parametric oscillator that converts the pulsed near-infrared output of a Titanium-Sapphire laser to wavelengths typically used for optical fiber transmissions. A second student has worked on a full-year project that involves testing and characterizing high speed metal-semiconductormetal photodetectors. The MSM detectors are state-of-the-art devices that operate at microwave frequencies by taking advantage of the speed of GaAs and the efficiency of interdigitated geometries.

Another advanced research project focuses on the application of high-speed optical devices to information processing. Specifically, students use multiple quantum well (MQW) modulators to solve problems related to digital optical logic and optical feedback architectures. The MQW devices are gallium arsenide and aluminum gallium arsenide (AlGaAs) devices whose optical absorption properties change relative to an applied electric field. Students apply their knowledge of semiconductor electronics and device physics to understand the basic theory of these III-V semiconductor devices and then use these modulators in applications which require knowledge of linear system theory, electromagnetic field theory, and photonics engineering. Students have designed and experimentally demonstrated such operations as alloptical AND and NAND gates and a linear wavelength conversion modulator. 


\section{INTEGRATION OF PROGRAMS}

\subsection{Integration objectives}

The current goal of the optical engineering education program is to address the needs of the Army while providing students with the background appropriate for a graduate of an ABET-accredited electrical engineering program. Current objectives include laser familiarization for every student at the Academy and in-depth study for an appropriate number of physics, chemistry, and electrical engineering majors. Within the electrical engineering program, the focus is on optical, optoelectronic, and electro-optic applications.

\subsection{Integration methodology}

Integration of optical engineering education in the electrical engineering program is based primarily on the Photonics Research Center, the photonics engineering course, the capstone engineering design program, and the advanced individual development program. The first formal exposure to lasers for all students comes at the end of the first semester of sophomore year when every student at that level tours the PRC as part of the core classical physics course. Members of the Photonics Research Center prepare a demonstration for each of the active experiments in progress. The demonstrations typically cover an overview of laser physics, laser specifications, laser operation, and a variety of commercial and military applications based on spectroscopy, photorefractives, multiple quantum well devices, and optoelectronic devices. More that a thousand students are broken down into small groups and worked through the series of demonstrations over a period of two weeks.

Electrical engineering majors are briefly exposed to optics in the junior-level modern physics course. However, they generally do not become actively involved in the optics education program until senior year. As seniors, approximately half of the electrical engineering majors take an electromagnetic fields course, EE383, and follow with the photonics engineering course, EE483. Students wishing to pursue the study of optics and lasers through other formal courses can choose from those described in section 2.5 .

A key part of the optics education program is the opportunity for individual research and team design. Some students work in the Photonics Research Center for one or two semesters in lieu of formal course work. These student often learn optics through hands-on work because the photonics engineering course is not available until the final semester. By combining experimental optics in the PRC with theory and applications in the photonics engineering course, these selected students are able to graduate with very strong qualifications. Electrical engineering majors have an opportunity to pursue optics education through the capstone design program. During the spring of 1995, three of the eight capstone design projects required students working in groups to design systems that were principally optical. Two of these teams of four to six students had one member with previous research in the PRC. On the other hand, some of the design team members had no formal instruction in optics beyond the demonstrations presented to all sophomores. This was a great opportunity for latter group to learn about optics from faculty and from classmates who had an understanding of optics from previous research in the PRC or from EE483.

The final entry point into the senior level portion of the optics education program is through the Academic Individual Advanced Development Program described in section 2.4. Occasionally, a cadet will choose to remain at West Point and work in the PRC during the summer between junior and senior year instead of going to an Army Research Laboratory facility for advanced development. The 120 hours of work completed over a three week period is nearly equivalent to a formal academic course. Several students have completed significant research projects during this time and then carried the work into the regular academic year as individual study or a capstone design project.

\subsection{Integration examples}

During the last academic year, two senior students completed individual research projects in the Photonics Research Center in the fall semester and used the experience with lasers and optics to contribute to a capstone design project in the spring. In the first example, one cadet completed the experimental setup and measured the response time of a $6.5 \mathrm{GHz}$ 
metal-semiconductor-metal GaAs detector. During the spring semester, he took EE483 and worked with three other students on a capstone design project which designed a feedback system to stabilize laser diodes. In the second example, another cadet characterized several multiple quantum well devices for a follow-on experiment. He had already taken EE483 during his junior year. In the spring he was the team leader for a group of six students whose project was to optically input characters into a photorefractive crystal and, using the output correlation peak intensity, design and build a processor-based system that would determine if the letters matched. These two examples are representative of how the PRC and the electrical engineering program have been combined to create a well-coordinated optics education program.

\subsection{Future plans}

At this time, the optics education program is working well and objectives are being met. The current program will be expanded to involve more students and more projects. An area will be set aside for military applications so students will have a better understanding of systems they will see after graduation.

\section{CONCLUSIONS}

The U.S. Military Academy has implemented an extensive optics education program. It is based on demonstrations presented to all cadets, followed by opportunities for formal course work, team design, and individual research. The Depratment of Electrical Engineering and Computer Science has been a prime advocate of the integrated program for cadets for many years. The Photonics Research Center is a major resource which supports photonic research and education for cadets and faculty. Graduates of the program gain an excellent experience in optical theory, applications, and experimentation.

1. D.M. Litynski, "The engineering curriculum at West Point two hundred years after Kosciuszko," Australasian Journal of Engineering Education Vol. 2, No. 2, 127-135, (February 1992).

2. D.M. Litynski, K.E. Reinhard and B.C. Tousley. "Integrating electromagnetic fields innovations in an undergraduate curriculum", Proceedings of the International Symposium on Electromagnetic Fields (ISEF95). September 1995. (to be published)

3. A.H. Sayles, B.C. Tousley, and B.L. Shoop, "Undergraduate electrical engineering photonics research at the United States Military Academy," Proceedings of the Annual Meeting of the American Society for Engineering Education, Middle Atlantic Section, November 1994. 